\title{
IN VITRO CYTOTOXICITY OF BIOSYNTHESIZED GOLD NANOPARTICLES FROM SHELLS OF PISTACIA VERA L
}

\author{
MADHUMITHRA S. K.a , BALASHANMUGAM P.b, MOSACHRISTAS K.c, TAMIL SELVI A. ${ }^{b}$, SUBASHINI R. ${ }^{*}$
}

aDepartment of Biomedical Engineering, SSN College of Engineering, Kalavakkam, Chennai, 603110, Tamil Nadu, India, bentre for Human and Organisational Resources Development (CHORD), CSIR-Central Leather Research Institute, Chennai, 600020, Tamil Nadu, India, cAvanz Bio Pvt. Ltd., Ganthipuram, East Tambaram, Chennai, 600059, Tamil Nadu, India Email: subashinir@ssn.edu.in

Received: 05 May 2018, Revised and Accepted: 06 Jun 2018

\begin{abstract}
Objective: To synthesize the gold nanoparticles by a biological method using the extract obtained from the shells of Pistacia vera ( $P$. vera) and to study its effective role in the anticancer activity.

Methods: The synthesis of gold nanoparticles using the extract obtained from the shells of Pistacia vera was confirmed by the color change and substantiating the same using ultraviolet (UV) visible spectroscopy. The size and the shape of the particles were studied using field emission scanning electron microscopy (FESEM). The stability of the nanoparticles was assessed by using the UV visible spectroscopy and Fourier-transform infrared spectroscopy (FTIR). The anticancer activity of the gold nanoparticles on the cancer cell lines was studied on PA1 ovarian cancer cell lines using 3-(4,5-Dimethylthiazol-2-yl)-2,5-diphenyltetrazolium bromide (MTT) assay. Nature of cell death was analyzed using the fluorescence microscopy.
\end{abstract}

Results: The ruby red color confirmed the formation of gold nanoparticles and it was substantiated by the absorption peak at 543.2 nm in the UV visible spectroscopy. The gold nanoparticles synthesized from the Pistacia vera shell showed the spherical shape and were in the size of around 10$40 \mathrm{~nm}$ when analyzed with FESEM. The different functional groups were indicated in the FTIR spectra which were consisting of phenol, alcohol, alkenes and aromatics.

Conclusion: The synthesis of the gold nanoparticle using the extract obtained from the shells of Pistacia vera has effective anticancer activity.

Keywords: Gold nanoparticles, Pistacia vera, Cytotoxicity, Apoptosis, Ovarian cancer cell lines, Fluorescence microscopy

(C) 2018 The Authors. Published by Innovare Academic Sciences Pvt Ltd. This is an open access article under the CC BY license (http://creativecommons.org/licenses/by/4.0/) DOI: http://dx.doi.org/10.22159/ijap.2018v10i4.27154

\section{INTRODUCTION}

Nanoparticles possess very small size in the molecular range and its physical and chemical properties different from that of the bulk and small molecules. The proliferating research area in biomedical fields like imaging and therapy covers the engineering nanoparticles. The interaction of the nanoparticle with the biological environment depends on the nature of the medium. This interaction is due to the presence of proteins and several other biomolecules present in the biological environment and this is known as biomolecular corona formation [1].

There has been keen interest in gold nanoparticles as their physical and chemical properties are depending on the size and shape of these particles [2]. Preparation of gold nanoparticles is not only easy but is also highly flexible since they can be synthesized in different shapes and sizes [3-4]. Due to different size and structure, the gold nanoparticles (AuNPs) has found a wide range of biomedical application, including imaging, radiotherapy, chemotherapy, photothermal therapy [5]. The clearance rate of gold nanoparticles from the body is still a barrier beside the particle's chemically inert nature. Hence, it is necessary to develop target-specific nanoparticles [6]. The toxicity of the nanoparticle is purely size dependent and was found to be deleterious in the range of 8 to 37 $\mathrm{nm}$ [7].

There are many methods for the synthesis of nanoparticles, which includes electrochemical, microwave assisted, thermal decomposition, etc. But the biosynthesis of nanoparticles from the fungi, bacteria, algae, and plants are eco-friendly [8] and can be used for pharmaceutical and biomedical applications since it involves no toxic substances for synthesis [9]. This method of synthesis has high potential and is economical [10].

The advancement in healthcare and technology has enormously increased the lifespan of the individual increasing the birth rate and decreasing the mortality rate. Despite this, there has also been an increase in different pathological conditions because of which people die. Cancer is one of the deadliest diseases ever known. According to the survey conducted by the National Cancer Institute of America, in 2014, an estimated 15,780 children and adolescents ages 0 to 19 were diagnosed with cancer and 1,960 died of the disease. Further, they also added that National expenditures for cancer care in the United States totaled nearly \$125 billion in 2010 and could reach $\$ 156$ billion in 2020. The AuNPs in cancer application is used for diagnosis of cancer in which the image quality is enhanced and in case of treatment, it is used for photodynamic therapy involving killing of cells by activating the photosensitizer using light and photothermal therapy in which the cells are destroyed by selectively heating the nanoparticles by using energy sources like laser [11].

It has been shown that the plant extracts from Salvia officinalis leaves, Pelargonium graveolens leaves, Lippia citriodora leaves, and Punica granatum fruit has served as green reactants in gold nanoparticles synthesis [12]. The genus Pistacia belongs to the Anacardiaceae family that comprise about 70 genera and over 600 species. Pistacia vera (P. vera) is the only species of the genus cultivated commercially and is used all over the world. In traditional Iranian medicine (TIM), different parts of $P$. vera, $P$. atlantica, $P$. khinjuk $P$. terebinthus, and $P$. lentiscus have been used for a long time as useful remedies for different diseases, for example, the fruit kernel of $P$. vera as a cardiac, stomach, hepatic, and brain tonic formulations $[13,14]$. P. vera contains major bioactive compounds such as monoterpenoids, sesquiterpenoids, volatile oil, diterpenoids and phenolic compounds and shows multiple biological actions like antioxidant, antimicrobial, anti-inflammatory, anti-hepatotoxic indicating its pharmaceutical values $[15,16]$. A recent study has demonstrated that the $P$. vera oleoresin displayed good anti-tumour activity [17]. Therefore, the objective of the study is to synthesize gold nanoparticles using shells of $P$. vera extract and their cytotoxic effect against ovarian cancer cell line was investigated. 


\section{MATERIALS AND METHODS}

\section{Materials and chemical reagents}

The shells of Pistacia vera (P. vera) were collected from the commercial market. Tetrachloroauric acid, also known as gold chloride $\left(\mathrm{HAuCl}_{4}\right)$, Bovine Serum (FBS), Dulbecco's Modified Eagle Medium (DMEM) and $0.25 \%$ trypsin-EDTA were obtained from Himedia Lab Private Limited, Mumbai, India. All other chemicals were purchased from Sigma-Aldrich (Saint Louis, Missouri, USA).

\section{Biosynthesis of gold nanoparticles}

The collected shells of $P$. vera were washed thoroughly with distilled water. The sample was shadow dried for $24 \mathrm{~h}$ and ground to coarse powder; $1.0 \mathrm{~g}$ of the ground shell sample was added to $20 \mathrm{ml}$ of distilled water and heated at $60{ }^{\circ} \mathrm{C}$ for $20 \mathrm{~min}$. The mixture was cooled to room temperature and filtered through Whatmann No. 1 filter paper. The aqueous extract was stored in a refrigerator for further studies [18]. Biosynthesis of gold nanoparticles was carried out following Balashanmugam et al. [19] method. The aqueous shells extract of $P$. vera was taken and added to $9.0 \mathrm{ml}$ of $1.0 \mathrm{mmol}$ of $\mathrm{HAuCl}_{4}$. The reaction was incubated at room temperature in dark condition for $24 \mathrm{~h}$ and observed for any change in color.

\section{UV visible spectroscopy}

The biological reduction of chloroaurate was recorded under UVvisible spectroscopy using PC based systronic double beam spectrophotometer 2202. The formation of ruby red color confirms the synthesis of AuNPs. The confirmation of color change was done by analyzing the absorption peak over the range of wavelength from $300 \mathrm{~nm}$ to $700 \mathrm{~nm}$.

\section{Stability of AuNPs}

The stability of AuNPs synthesized from the shells of $P$. vera was recorded between $300 \mathrm{~nm}$ and $700 \mathrm{~nm}$ at different time intervals such as $6 \mathrm{~h}, 12 \mathrm{~h}, 18 \mathrm{~h}, 24 \mathrm{~h}, 10^{\text {th }}$ day, $20^{\text {th }}$ day, and $30^{\text {th }}$ day. The absorbance of the solutions was measured using the abovementioned instrument.

\section{Field emission scanning electron microscopy (FESEM) and energy dispersive X-ray spectroscopy (EDX)}

A drop of AuNPs was placed on aluminium foil and allowed to stand for $2 \mathrm{~min}$, and the excess solution was removed using a blotting paper allowed to dry at $50^{\circ} \mathrm{C}$. FESEM observations were made on a HITACHI-SO-6600. EDX analyses of different elements were recorded with the above instrument.

\section{$\mathrm{X}$-ray diffraction (XRD)}

The crystalline nature of the gold nanoparticles was revealed by XRD analysis. The gold nanoparticles were placed on a glass disk ( $\sim 5 \mathrm{~mm}$ diameter) for drying and then mounted in the specimen port of the diffractometer. The XRD pattern was observed with $\mathrm{Cu}$ $\mathrm{K} \alpha$ radiation with the operating condition at $40 \mathrm{kV}, 100 \mathrm{~mA}$ and scanned in the $2 \theta$ range from $20^{\circ}$ to $80^{\circ}$ with step size $0.02^{\circ}$ per second.

\section{Fourier transform infrared spectroscopy (FTIR)}

The formation of AuNPs and its stabilizing biomolecules were analyzed using FTIR (Perkin-Elmer spectrum). All measurements were carried out in the range of $400-4000 \mathrm{~cm}^{-1}$ at a resolution of 4 $\mathrm{cm}^{-1}$. The biomolecule that is present in the extract which was responsible for capping was identified. The various modes of vibrations were identified and assigned to determine the different functional groups present in the sample.

\section{In vitro cytotoxicity by MTT assay}

The PA1 ovarian cancer cell lines were obtained from National centre for cell sciences (NCCS), Pune, India. The cells were maintained in DMEM medium supplemented with $10 \%(\mathrm{v} / \mathrm{v})$ heat-inactivated fetal bovine serum, penicillin $(100 \mathrm{U} / \mathrm{ml})$ and streptomycin $(100 \mu \mathrm{g} / \mathrm{ml})$ in a $95 \%$ air humidified incubator at $37{ }^{\circ} \mathrm{C}$ with $5 \% \mathrm{CO}_{2}$. The cytotoxic effect of biosynthesized AuNPs was tested against PA1 cancer cell line by 3-(4,5dimethylthiazol-2-yl)-2,5-diphenyltetrazolium bromide (MTT) assay
[20]. The cell line was seeded in 96-well microplates $\left(1 \times 10^{6}\right.$ cells $\left./ \mathrm{ml}\right)$ and incubated at $37^{\circ} \mathrm{C}$ for $24 \mathrm{~h}$ in an incubator and allowed to grow to $90 \%$ confluence. After the incubation period, the medium was removed and the cancer cells were treated with biosynthesized AuNPs at increasing concentrations of $5,10,20,40,60,80$ and $100 \mu \mathrm{g} / \mathrm{ml}$, in triplicate manner; non-treated cells were used as a control and incubated for $24 \mathrm{~h}$. The incubated treated cells were then subjected to 20 $\mu \mathrm{l}$ of MTT solution $(5 \mathrm{mg} / \mathrm{ml})$ and allowed to stand for $4 \mathrm{~h}$ at $37^{\circ} \mathrm{C}$ in the dark. The formazan crystals were dissolved using $100 \mu \mathrm{l}$ dimethyl sulphoxide (DMSO) and the absorbance was read spectrophotometry at $570 \mathrm{~nm}$ using enzyme-linked immunosorbent assay (ELISA) plate reader. The percentage of cell viability was expressed as

$$
\text { Cell viability }(\%)=\frac{\text { Absorbance of treated cells }}{\text { Absorbance of control cells }} \times 100
$$

\section{Analysis of apoptosis}

The PA1 cells were seeded into two 6-well plates at $5 \times 10^{4}$ cells/well, separately and allowed to attain $>90 \%$ confluence. The cells were treated with an $\mathrm{IC}_{50}$ concentration of AuNPs for $24 \mathrm{~h}$. The one plate with monolayer cells was washed with PBS, fixed in methanol: acetic acid (3:1, v/v) for $10 \mathrm{~min}$ and stained with 50 $\mu \mathrm{g} / \mathrm{ml}$ propidium iodide (PI) for $20 \mathrm{~min}$. The second plate was washed with PBS and stained with $5 \mu \mathrm{l}$ of acridine orange (AO, 100 $\mu \mathrm{g} / \mathrm{ml}$ ) and $5 \mu \mathrm{l}$ of ethidium bromide (EB, $100 \mu \mathrm{g} / \mathrm{ml}$ ). The morphological changes in the stained cells, the apoptotic nuclei (intensely stained, fragmented nuclei and condensed chromatin) were observed by FLoid cell imaging fluorescent microscopy [19].

\section{RESULTS AND DISCUSSION}

\section{Biosynthesis of gold nanoparticles}

The aqueous extract of the shells of Pistacia vera reduced $\mathrm{HAuCl}_{4}$ and the gold nanoparticles were synthesized indicated from the color change to ruby red after $24 \mathrm{~h}$. A study on the biosynthesis of gold nanoparticles from using the extract of cardamom and analysis of the effect of $\mathrm{pH}$ on synthesis involved the use of cardamom as a reducing agent for the synthesis [21]. The formation of ruby red color indicated the biosynthesis of AuNPs as shown in fig. 1. The color change to ruby red during the synthesis of the gold nanoparticles is due to the excitation of surface plasmon vibrations, which is stated as a characteristic feature of synthesized nanoparticles in a study of the diagnostic and therapeutic application of gold nanoparticles depending on their synthesis and characterization [22]. The absorption peak was recorded at $543.2 \mathrm{~nm}$ in the UV-visible spectra, confirming the synthesis of AuNPs as illustrated in fig. 1. The peak of the nanoparticles is broadened in the absorption spectra. For the biological and biomedical application, it is found that the broadening of the peak in the absorption spectra indicates the polydispersion of the nanoparticles from a study involving the peak of absorption and properties of scattering of gold nanoparticles [23].

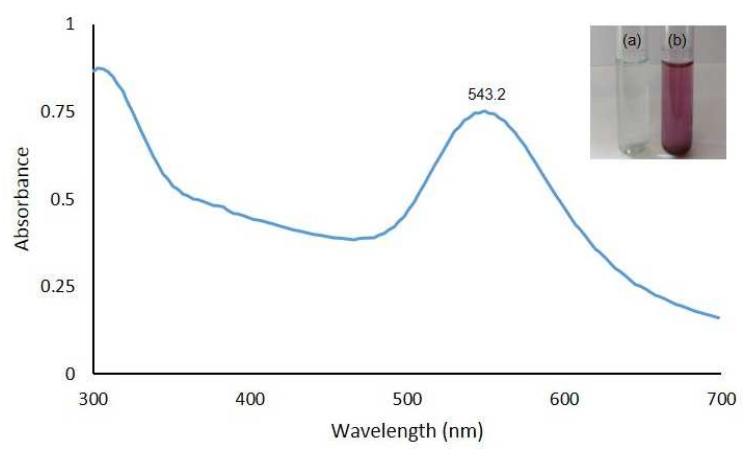

Fig. 1: UV-visible spectrum of AuNPs synthesized from the shells of Pistacia vera $\mathrm{L}$. Inset shows biosynthesized AuNPs. (a) control (before synthesis), (b) test (after synthesis)

\section{Stability of AuNPs}

The stability of the biosynthesized AuNPs was evaluated under UVvisible spectroscopy at different durations (6 h-1 mo). It was 
recorded that with increased contact time, the peak becomes sharper. The reaction had started within $6 \mathrm{~h}$, and the surface plasmon resonance showed a peak at $538.6 \mathrm{~nm}$. There was a shift in the peak to $540.5 \mathrm{~nm}$ at $12 \mathrm{~h}$ and remained up to $18 \mathrm{~h}$. At $24 \mathrm{~h}$, the peak was observed at $543.2 \mathrm{~nm}$ and the $30 \mathrm{~d}$ old sample exhibited the stable peak of surface plasmon resonance at $543.2 \mathrm{~nm}$. These results showed that there is no alteration in the peak for a period of one month of incubation, thus indicating the higher stability of biosynthesized AuNPs (fig. 2). The band of surface plasmon resonance at a constant wavelength over a period of one month with the increase in the intensity values was found to be stable by analyzing the UV-visible spectra of the synthesized gold and silver nanoparticles [24]. In this study, a similar increase in the peak intensity over the period of $24 \mathrm{~h}$ when the AuNPs were synthesized by reduction to $30^{\text {th }}$ day was observed indicating that it is stable for about a month.

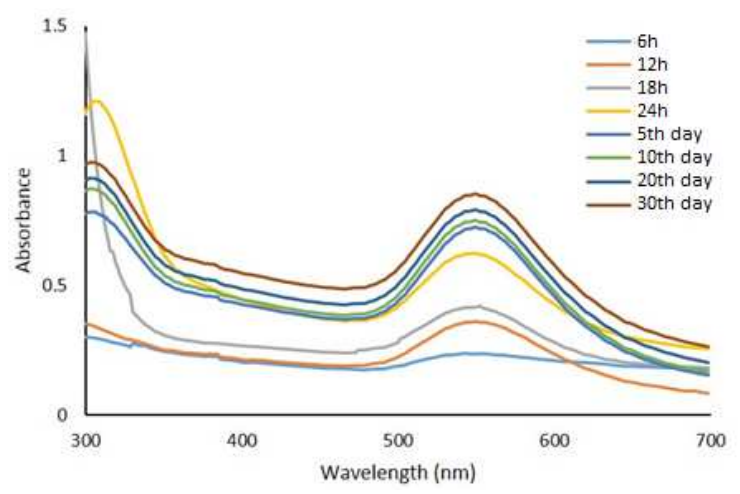

Fig. 2: The stacked UV-visible spectra of biosynthesized AuNPs over a period of one month at different time intervals (Number of experiments, $n=8$ )

Field emission scanning electron microscopy (FESEM) and energy dispersive X-ray spectroscopy (EDX)

The biosynthesized AuNPs were predominantly in a spherical shape with a diameter ranging between 10 to $40 \mathrm{~nm}$ which was observed from the inset (A) of fig. 3. Jeyaraj et al. [25] studied and analyzed the size, shape,and dispersion of the silver nanoparticle using the images obtained from field emission microscopy and stated that polydispersion is represented by no agglomeration. In this study also the agglomeration is absent and not definite indicating the polydispersion of the synthesized nanoparticles. The EDX spectrum showed sharp peaks identical to elemental gold, confirming the presence of biosynthesized AuNPs which could be seen from the inset (B) of fig. 3. A research on the synthesis of gold and silver nanoparticles using algae had used the EDS spectrum to depict the efficient reduction of the $\mathrm{Au}^{3+}$ to $\mathrm{Au}^{\circ}$ and confirmed the formation of elemental gold from the reduction reaction [26].

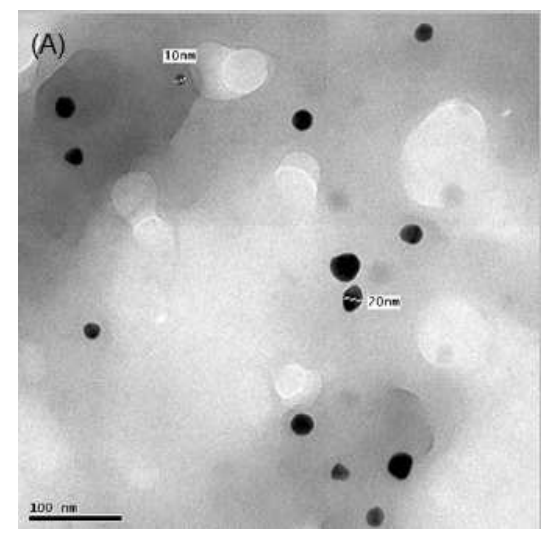

(B)

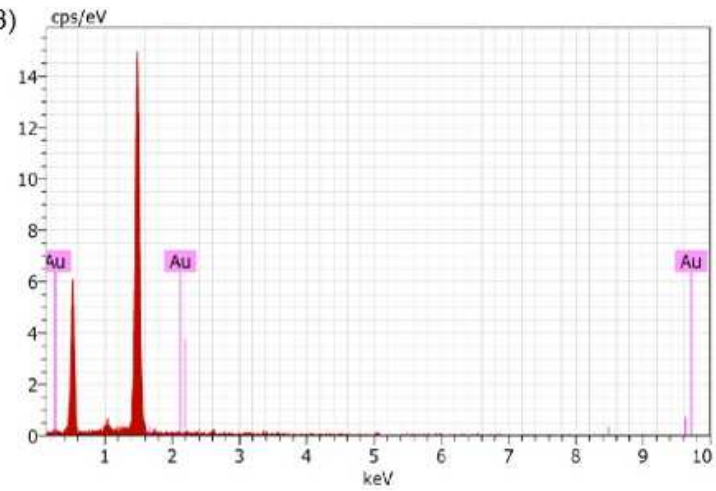

Fig. 3: Characterization of biosynthesized AuNPs (A) FESEM image of AuNPs, (B) EDX spectrum

\section{X-ray diffraction (XRD)}

The XRD analysis showed three distinct Bragg reflection peaks corresponding to (111), (200), (220) and (311) lattice planes at 38.21 $\circ, 44.39^{\circ}, 64.62^{\circ}$ and $77.59^{\circ}$ respectively are indexed to the facecentred cubic structure of gold when compared to standard JCPDS file number 65-2870. The XRD pattern clearly indicated that the biosynthesized AuNPs are crystalline in nature (fig. 4). The strongest intensity of the diffraction peak of (111) lattice plane compared to the other peaks suggests its predominant orientation. The predominant orientation in the (111) plane with a predominant peak in the XRD compared to the other peaks indicated that the average size of the nanoparticles to be around $15 \mathrm{~nm}$ using the Debye-Scherrer equation for calculating size [27]. A similar predominant peak is observed in the XRD in this study substantiating that the average size is about $15 \mathrm{~nm}$ that can also be seen in the FESEM of the study. In a research on the synthesis of gold and silver nanoparticles using leaf extract, the gold nanoparticles showed characteristic diffraction peaks $38.21^{\circ}, 44.39^{\circ}$, $64.62^{\circ}, 77.59^{\circ}, 81.75^{\circ}, 98.16^{\circ}, 110.89^{\circ}$ and $115.27^{\circ}$ which is used for concluding the face-centred cubic (FCC) nature of gold nanoparticles [28].

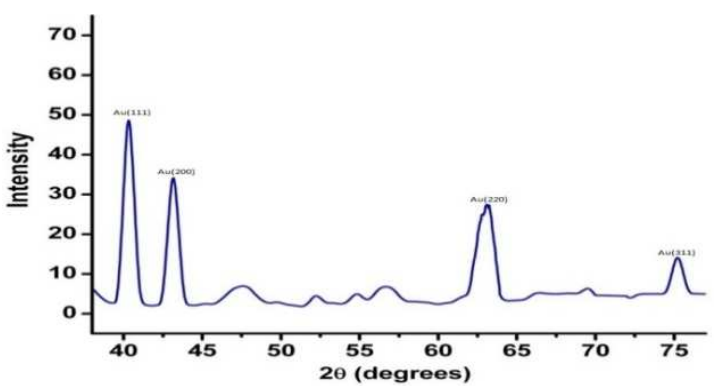

Fig. 4: XRD pattern of biosynthesized AuNPs

\section{Fourier transform infrared (FTIR) spectroscopy}

The interaction of gold nanoparticles with biomolecules of aqueous shell extract of $P$. vera was inferred by FTIR analysis. The FTIR spectra show the functional groups' vibration of $P$. vera shells extract and biosynthesized AuNPs, respectively (fig. 5). A strong, broad peak recorded at $3339.62 \mathrm{~cm}^{-1}$ due to $0-\mathrm{H}$ group stretching vibrations indicating the presence of phenol and alcohol. An absorption band appeared at $1637.25 \mathrm{~cm}^{-1}$ corresponding to $\mathrm{C}=\mathrm{C}$ stretching vibrations confirming the presence of alkenes. In the research on biofuel extracted from the shells of pista, the FTIR spectrum was used for the functional group analysis of bio-oil. It was stated that the presence of phenols and alcohols is indicated by the $\mathrm{O}-\mathrm{H}$ stretching vibrations between 3200 and $3400 \mathrm{~cm}^{-1}$ and the presence of alkenes and aromatics is indicated by the $\mathrm{C}=\mathrm{C}$ stretching vibrations between 1575 and $1675 \mathrm{~cm}^{-1}$ [29]. The depth and width of the band are indicative of the intensity and abundance of the particular functional group in that band [30]. 

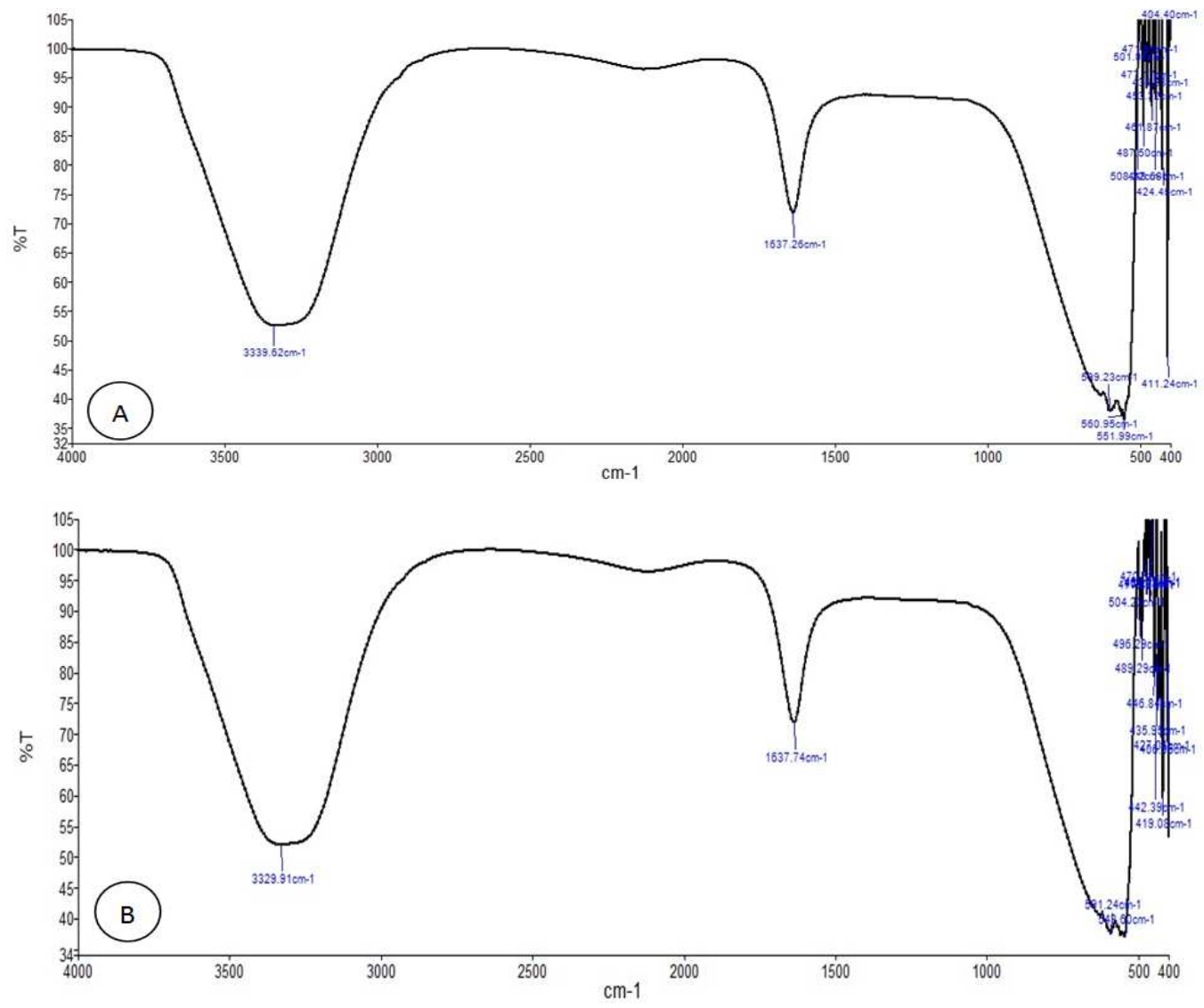

Fig. 5: FTIR spectrum (A) aqueous shell extract of Pistacia vera, (B)biosynthesized AuNPs

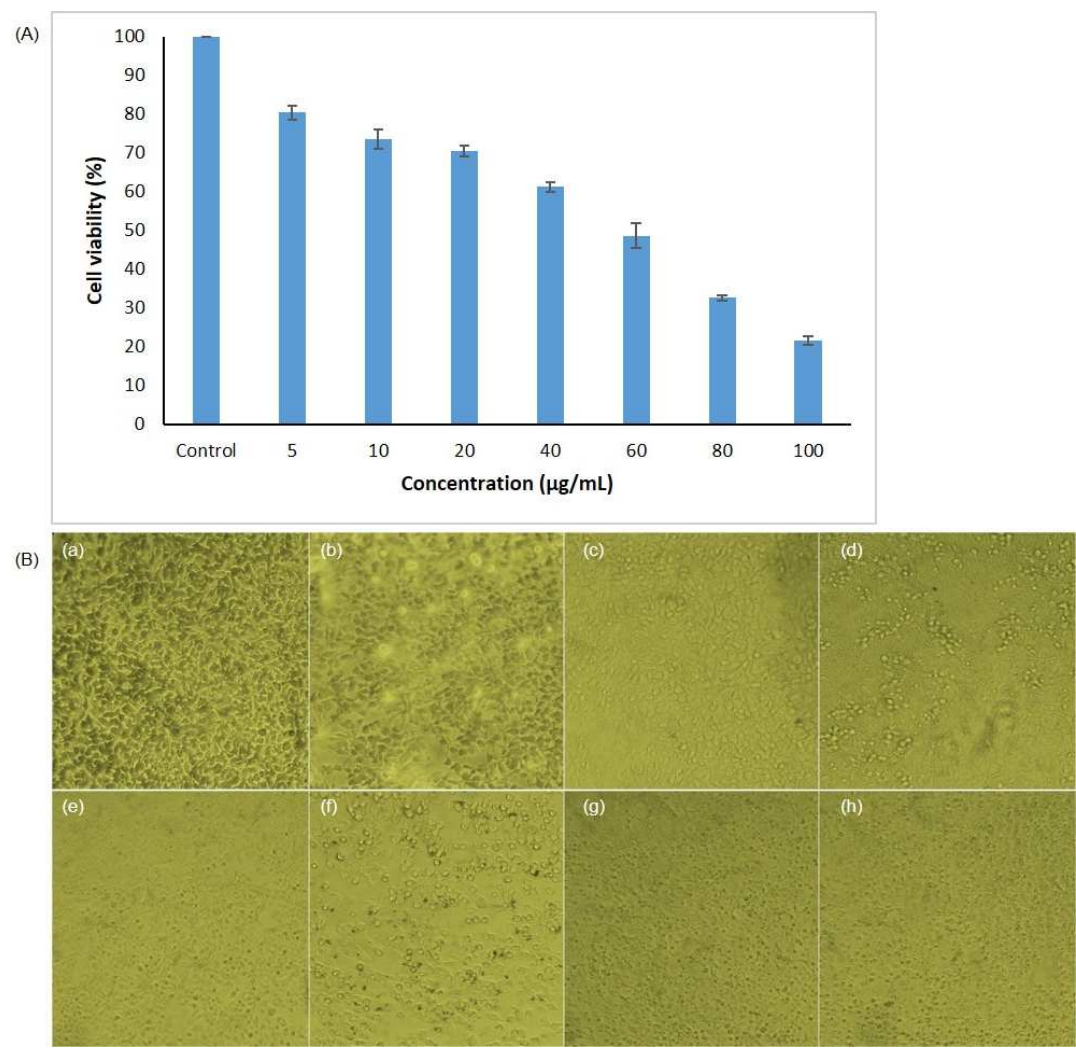

Fig. 6: (A) Cytotoxicity effect of different concentration of biosynthesized AuNPs on PA1 ovarian cell line. Values are given as mean \pm SD for each concentration (n=8). (B) Cytotoxic effect of biosynthesized AuNPs on PA1 cell line(n=8). (a) Control, (b) 5, (c) 10, (d) 20, (e) 40, (f) 60, (g) 80 and (h) $100 \mu \mathrm{g} / \mathrm{ml}$ 


\section{In vitro cytotoxicity}

The in vitro cytotoxicity of AuNPs was examined on PA1 ovarian cell line in terms of the effect of nanoparticles on cell proliferation by the MTT assay [31, 32]. The dose-dependent inhibition was observed in AuNPs treated PA1 cells and the increase in the concentration of AuNPs $(5,10,20,40,60,80$ and $100 \mu \mathrm{g} / \mathrm{ml})$ showed increased cytotoxicity in PA1 cells which are shown in the inset (A) of fig. 6. The IC $\mathrm{I}_{50}$ value for PA1 cells was recorded at $60 \mu \mathrm{g} / \mathrm{ml}$. The cells were found clumped, rounded. A prominent decrease in the cell viability was observed in AuNPs (different concentrations) treated cells when compared to the control which is shown in the inset (B) of fig. 6. Balashanmugam et al. [19] studied the in vitro cytotoxicity of the gold nanoparticles on three cancer cell lines using the gold nanoparticles concluded that the increase in the concentration of AuNPs resulted in an increase in cell death and concluded that the nanoparticles they synthesized possess anticancer properties. There has been increase in toxicity and cell death in this study with the increase in the concentration of biosynthesized gold nanoparticles on the PA1 ovarian cancer cell line. On the other hand, the normal cells had no toxic effect of the gold nanoparticles produced from the extract of Pistacia vera and hence, it can be effectively used as an anticancer drug.

\section{Analysis of apoptosis of PA1 cells under fluorescence microscope}

The apoptotic changes and nuclear condensation induced by biosynthesized AuNPs was observed using PI staining method under the fluorescent microscope. The PI stained PA1 cells showed very fewer apoptotic cells in the control, whereas an increased number of apoptotic cells was found in the cells treated at $\mathrm{IC}_{50}$ of AuNPs which can be seen in the (A) of fig. 7. Singh et al. [33] studied the apoptosis using the propidium iodide by treating the cells with increasing insulin concentration. They observed that on treating with insulin the number of viable cells increased with fewer red cells in the microscopic image. This approach is adoptedin this research to study the cell apoptosis induced by the gold nanoparticles, which showed an increase in the number of red cells after treating with propidium podide indicating that effectiveness of the gold nanoparticle. The biosynthesized AuNPs treated cells exhibited condensed chromatin and bright nuclei (marked by red fluorescence) than the control cells. The apoptosis-associated changes of cell membranes during the process of apoptosis were identified using dual $\mathrm{AO} / \mathrm{EB}$ staining under the fluorescent microscope [34]. Baskić et al. [35] studied the apoptotic nature of cell death using AO/EB staining in which it had been stated that the green nuclei with well-defined structures indicate healthy cells. The control cells upon this staining, in this study, exhibit only such green structures which implies that they are healthy and not affected by the gold nanoparticles. There was no significant apoptosis detected in the control cells whereas the AuNPs treated PA1 cells resulted in morphological apoptotic changes which can be observed in the inset (B) of fig. 7. The control cells showed uniform bright green nuclei and cytoplasm. The cells treated with AuNPs exhibited early apoptosis, and late apoptotic cells having bright green patches of cells with intact membrane and green nuclei representing their perinuclear chromatin condensation, asymmetrically localized light orange crescent nuclei with increased volume and dark orange fluorescence depicting their chromatin in either fragmented or condensed form. Both the viable and the non-viable cells take up AO stain and emit green fluorescence on binding with DNA and red fluorescence on binding with RNA. The EB stain is taken up only by non-viable cells emitting red fluorescence on intercalating with DNA. An organized viable cell was observed emitting a uniform bright green fluorescence. In the early apoptotic stage, bright green patches of cells with intact membrane and green nuclei representing their perinuclear chromatin condensation were detected. The apoptotic cells showed asymmetrically localized light orange crescent nuclei with increased volume. The late-stage apoptotic cells emitted dark orange fluorescence depicting their chromatin in either fragmented or condensed form [36]. Hence, in this study the images of AO/EB staining of the cancer cell lines confirms no necrotic cell death as there is no red fluorescence.
(A)

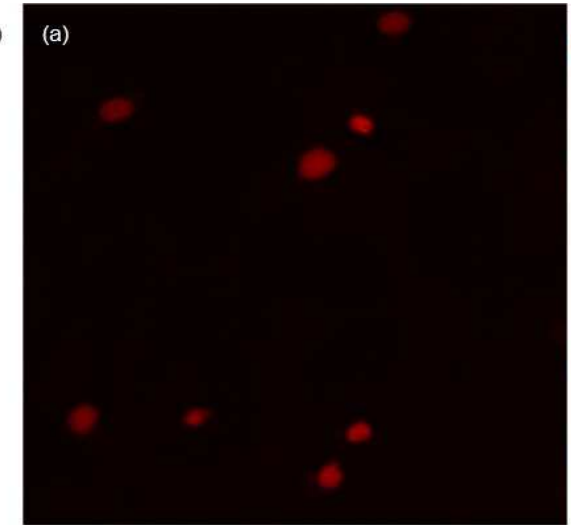

(B)

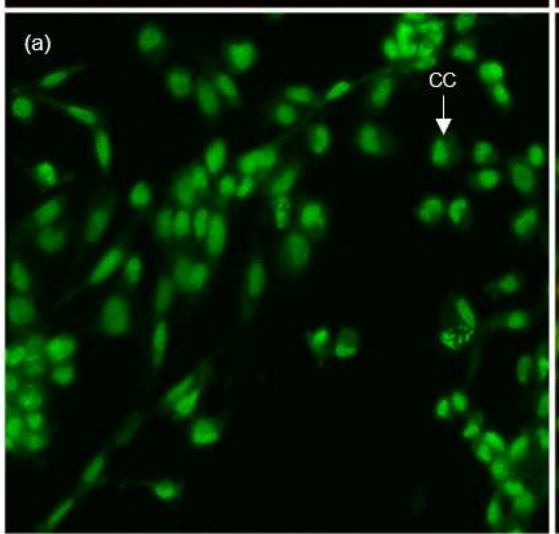

\section{(b)}
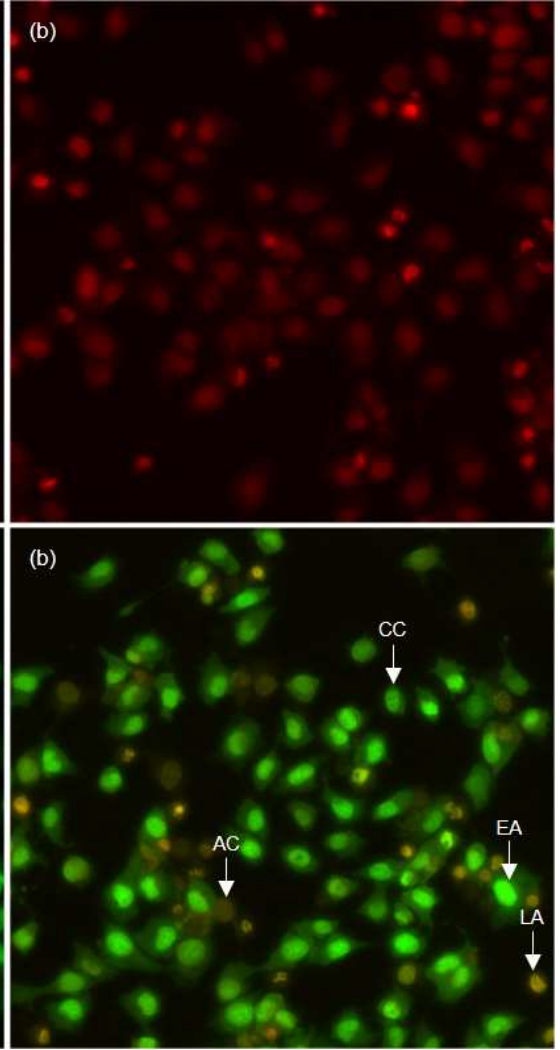

Fig. 7: Morphological changes of apoptotic cells stained with (A) propidium iodide (PI) and (B) acridine orange and ethidium bromide (AO/EB) under fluorescence microscopy. (a) PA1 control cells, (b) AuNPs treated PA1 cells. CC-Control cells, EA-Early apoptotic cells, ACapoptotic cells, LA-Late apoptotic cells 


\section{CONCLUSION}

The synthesis of nanoparticles using bio-waste is gaining popularity because of its low-cost and eco-friendly nature compared to widely known chemical and physical methods. The spherical shaped biosynthesized AuNPs exhibited cytotoxic activity against ovarian cancer by inducing apoptosis in PA1 cells. In biomedical view, the role of biosynthesized AuNPs seems to be promising and thus can be represented as a novel therapeutic agent for the diagnosis and treatment of cancer cells. The future work should implement DNA fragmentation, cell cycle analysis, and in vivo studies to substantiate the anticancer properties of biosynthesized AuNPs.

\section{ACKNOWLEDGEMENT}

The authors would like to thank The Director, Avanz Bio Pvt. Ltd, Chennai, for providing the laboratory facilities. They also thank CSIR-CLRI, Chennai and SRM University, Chennai for providing the instrumentation facility.

\section{AUTHORS CONTRIBUTIONS}

All the author have contributed equally

\section{CONFLICTS OF INTERESTS}

The authors report no conflicts of interest in performing this work

\section{REFERENCES}

1. Kadian R. Nanoparticles: a promising drug delivery approach. Asian J Pharm Clin Res 2018;11:30-5.

2. Pandey P, Dahiya M. A brief review on inorganic nanoparticles. J Crit Rev 2014;3:18-26.

3. Bastús NG, Comenge J, Puntes V. Kinetically controlled seeded growth synthesis of citrate-stabilized gold nanoparticles of up to $200 \mathrm{~nm}$ : size focusing versus Ostwald ripening. Langmuir. 2011;27:11098-105.

4. Grzelczak M, Perez-Juste J, Mulvaney P, Liz-Marzan LM. Shape control in gold nanoparticle synthesis. Chem Soc Rev 2008;37:1783-91.

5. Kumar P, Roy I. Applications of gold nanoparticles in clinical medicine. Int J Pharm Pharm Sci 2016;8:11-6.

6. Zhang X. Gold nanoparticles: recent advances in the biomedical applications. Cell Biochem Biophys 2015;72:771-5.

7. Chen YS, Hung YC, Liau I, Huang GS. Assessment of the in vivo toxicity of gold nanoparticles. Nanoscale Res Lett 2009;4:858-64.

8. Antony E, Sathiavelu M, Arunachalam S. Synthesis of silver nanoparticles from the medicinal plant Bauhinia acuminata and biophytum sensitivum-a comparative study of its biological activities with plant extract. Int J Appl Pharm 2017;9:22-9.

9. Pantidos N, Horsfall LE. Biological synthesis of metallic nanoparticles by bacteria, fungi and plants. J Nanomed Nanotechnol 2014;5:1-10.

10. Singh P, Kim YJ, Zhang D, Yang DC. Biological synthesis of nanoparticles from plants and microorganisms. Trends Biotechnol 2016;34:588-99.

11. Dykman L, Khlebtsov N. Gold nanoparticles in biomedical applications: recent advances and perspectives. Chem Soc Rev 2012;41:2256-82.

12. Elia P, Zach R, Hazan S, Kolusheva S, Porat ZE, Zeiri Y. Green synthesis of gold nanoparticles using plant extracts as reducing agents. Int J Nanomed 2014;9:4007-21.

13. Bozorgi M, Memariani Z, Mobli M, Salehi Surmaghi MH, ShamsArdekani MR, Rahimi R. Five pistacia species $(P$. vera, $P$. atlantica, $P$. terebinthus, $P$. khinjuk, and $P$. lentiscus): a review of their traditional uses, phytochemistry, and pharmacology. Sci World J 2013;1-33. http://dx.doi.org/10.1155/2013/219815.

14. Kashaninejad M, Mortazavi A, Safekordi A, Tabil LG. Some physical properties of pistachio (Pistacia vera L.) nut and its kernel. J Food Eng 2006;72:30-8.

15. Roitman JN, Merrill GB, Beck JJ. Survey of ex situ fruit and leaf volatiles from several Pistacia cultivars grown in California. J Sci Food Agric 2011;91:934-42.
16. Goli AH, Barzegar M, Sahari MA. Antioxidant activity and total phenolic compounds of pistachio (Pistachia vera) hull extracts. Food Chem 2005;92:521-5.

17. Almehdar $\mathrm{H}, \mathrm{Abdallah} \mathrm{HM}, \mathrm{Osman} \mathrm{AM}, \mathrm{Abdel}$ Sattar EA. In vitro cytotoxic screening of selected Saudi medicinal plants. J Nat Med 2012;66:406-12.

18. Mubarak Ali D, Thajuddin N, Jeganathan K, Gunasekaran M. Plant extract mediated synthesis of silver and gold nanoparticles and its antibacterial activity against clinically isolated pathogens. Colloids Surf B 2011;85:360-5.

19. Balashanmugam P, Durai P, Balakumaran MD, Kalaichelvan PT. Phytosynthesized gold nanoparticles from $C$. roxburghii DC. leaf and their toxic effects on normal and cancer cell lines. J Photochem Photobiol B 2016;165:163-73.

20. Mosmann T. Rapid colorimetric assay for cellular growth and survival: application to proliferation and cytotoxicity assays. J Immunol Methods 1983;65:55-63.

21. Singh AK, Srivastava ON. One-step green synthesis of gold nanoparticles using black cardamom and effect of $\mathrm{pH}$ on its synthesis. Nanoscale Res Lett 2015;10:353-65.

22. Verma HN, Singh P, Chavan RM. Gold nanoparticle: synthesis and characterization. Vet World 2014;7:72-7.

23. Jain PK, Lee KS, El-Sayed IH, El-Sayed MA. Calculated absorption and scattering properties of gold nanoparticles of different size, shape, and composition: applications in biological imaging and biomedicine. J Phys Chem B 2006;110:7238-48.

24. Kasthuri J, Veerapandian S, Rajendiran N. Biological synthesis of silver and gold nanoparticles using apiin as reducing agent. Colloids Surf B 2009;68:55-60.

25. Jeyaraj M, Rajesh M, Arun R, Mubarak Ali D, Sathishkumar G, Sivanandhan G, et al. An investigation on the cytotoxicity and caspase-mediated apoptotic effect of biologically synthesized silver nanoparticles using Podophyllum hexandrum on human cervical carcinoma cells. Colloids Surf B 2013;102:708-17.

26. Castro L, Blazquez ML, Munoz JA, Gonzalez F, Ballester A. Biological synthesis of metallic nanoparticles using algae. IET Nanobiotechnol 2013;7:109-16.

27. Taha A, Shamsuddin M. Biosynthesis of gold nanoparticles using Psidium guajava leaf extract. Malaysian J Fundamental Appl Sci 2013;9:119-22.

28. Dwivedi AD, Gopal K. Biosynthesis of silver and gold nanoparticles using Chenopodium album leaf extract. Colloids Surf A 2010;369:27-33.

29. Demiral İ, Atilgan NG, Şensoz S. Production of biofuel from soft shell of pistachio (Pistacia vera L.). Chem Eng Commun 2008;196:104-15.

30. Açıkalın K, Karaca F, Bolat E. Pyrolysis of pistachio shell: effects of pyrolysis conditions and analysis of products. Fuel 2012;95:169-77.

31. Preethi R, Padma PR. Anticancer activity of silver nanobioconjugates synthesized from piper betle leaves extract and its active compound eugenol. Int J Pharm Pharm Sci 2016;8:201-5.

32. Ashwini S, Suresh Babut V, Saritha, Manjula Shantaram. Seaweed extracts exhibit anticancer activity against HeLa cell lines. Int J Curr Pharm Res 2017;9:114-7.

33. Singh N, Ranjan V, Deeba Zaidi HS, Singh A, Lodha D, Sharma R, et al. Insulin catalyzes the curcumin-induced wound healing: an in vitro model for gingival repair. Indian $\mathrm{J}$ Pharmacol 2012;44:458-62.

34. Preethi R, Padma PR. Green synthesis of silver nanobioconjugates from Piper betle leaves and its anticancer activity on A549 cells. Asian J Pharm Clin Res 2016;9:252-7.

35. Baskić D, Popovic S, Ristic P, Arsenijevic NN. Analysis of cycloheximide-induced apoptosis in human leukocytes: fluorescence microscopy using annexin $\mathrm{V} /$ propidium iodide versus acridin orange/ethidium bromide. Cell Biol Int 2006;30:924-32.

36. Curcic MG, Stankovic MS, Mrkalic EM, Matovic ZD, Bankovic DD Cvetkovic DM, et al. Antiproliferative and proapoptotic activities of methanolic extracts from Ligustrum vulgare L. as an individual treatment and in combination with palladium complex. Int J Mol Sci 2012;13:2521-34. 